Acta Crystallographica Section B

Structural

Science

ISSN 0108-7681

Koji Nishi, Akira Hidaka and Yoshinobu Yokomori*

National Defense Academy, Hashirimizu, Yokosuka 239-8686, Japan

Correspondence e-mail: yokomori@nda.ac.jp

\title{
Structure of toluene6.4-ZSM-5 and the toluene disproportionation reaction on ZSM-5
}

The structure of a high-loading complex of ZSM-5 with 6.4 toluene molecules per unit cell has been determined by singlecrystal X-ray diffraction. At least three kinds of toluene molecules were identified in the unit cell. Two disordered toluene molecules were located at the intersection of the straight and sinusoidal channels, the third in the sinusoidal channel. One (TOL1) of the two toluene orientations at the intersection was similar to that of $p$-dichlorobenzene at the intersection in high-loaded H-ZSM-5/p-xylene (hereafter 8PARA) and high-loaded H-ZSM-5/p-dichlorobenzene (hereafter 8PDCB) complexes, respectively. The other toluene orientation (TOL2) at the intersection was similar to those of $p$-xylene or $p$-dichlorobenzene at the intersection in the lowloaded $p$-dichlorobenzene complex (hereafter 2.6PDCB). A third toluene orientation (TOL3) existed in the sinusoidal channel; its orientation was similar to those of $p$-xylene and $p$ dichlorobenzene in the sinusoidal channels in 8PARA and 8PDCB complexes, respectively. If the occupancy of TOL2 at the intersection increases with temperature, TOL2 will connect with TOL3 in the sinusoidal channel and form the intermediate diphenylmethane

\section{Introduction}

The aluminosilicate ZSM-5 has been of interest due to its wide applicability as a shape-selective catalyst (Eylem et al., 1996). The sorbate-ZSM-5 structure has been investigated by X-ray single-crystal diffraction and X-ray powder diffraction (Olson et al., 1981; Price et al., 1982; van Koningsveld, 1987; Yokomori \& Idaka, 1999; van Koningsveld et al., 1989, 1996; van Koningsveld \& Jansen, 1996; Reck et al., 1996; Mentzen, 1989). At present, aromatic sorbate-ZSM-5 structures may be grouped into two classes:

(i) Low-loading group (4 or less sorbate per unit cell), space group Pnma or $P n 2_{1} a ; \alpha 2$ (the angle between the positive $a$ axis and the normal to the benzene ring plane) $\simeq 45^{\circ}$. Structures that fall into this category include 2.6PDCB (van Koningsveld, Jansen \& Man, 1996), p-nitroaniline3.7-ZSM-5 (Reck et al., 1996), naphthalene3.7-ZSM-5 (Klein et al., 1994; van Koningsveld \& Jansen, 1996).

(ii) High-loading group (over 4 sorbate per unit cell); space group $P 2{ }_{1} 2_{1} 2_{1} ; \alpha 2 \simeq 150^{\circ}$. This category includes 8PARA (van Koningsveld et al., 1989) and 8PDCB (van Koningsveld, Jansen \& van Bekkum, 1996).

The acid-catalyzed disproportionation of toluene to benzene and xylenes has been extensively investigated in ZSM-5
Received 14 July 2004 Accepted 28 January 2005 
Table 1

Experimental details.

\begin{tabular}{|c|c|}
\hline \multicolumn{2}{|l|}{ Crystal data } \\
\hline Chemical formula & $\mathrm{O}_{48} \mathrm{Si}_{24} \cdot \mathrm{C}_{7} \cdot 0.614 \mathrm{C}_{7} \mathrm{H}_{12.80}$ \\
\hline$M_{r}$ & 1590.25 \\
\hline Cell setting, space group & Orthorhombic, $P 2_{1} 2_{1} 2_{1}$ \\
\hline$a, b, c(\AA)$ & $20.0990(4), 19.8440(3), 13.4240(2)$ \\
\hline$V\left(\AA^{3}\right)$ & $5354.1(2)$ \\
\hline$Z$ & 4 \\
\hline$D_{x}\left(\mathrm{Mg} \mathrm{m}^{-3}\right)$ & 1.973 \\
\hline Radiation type & $\mathrm{Cu} K \alpha$ \\
\hline No. of reflections for cell parameters & 5636 \\
\hline$\theta$ range $\left({ }^{\circ}\right)$ & $0.6-0.7$ \\
\hline$\mu\left(\mathrm{mm}^{-1}\right)$ & 6.49 \\
\hline Temperature (K) & 293 \\
\hline Crystal form, colour & Cube, colourless \\
\hline Crystal size (mm) & $0.10 \times 0.07 \times 0.05$ \\
\hline \multicolumn{2}{|l|}{ Data collection } \\
\hline Diffractometer & DIP Image plate \\
\hline Data collection method & Image plate \\
\hline Absorption correction & $\begin{array}{l}\text { Empirical (using intensity measure- } \\
\text { ments) }\end{array}$ \\
\hline$T_{\min }$ & 0.609 \\
\hline$T_{\max }$ & 0.723 \\
\hline $\begin{array}{l}\text { No. of measured, independent and } \\
\text { observed reflections }\end{array}$ & $17530,9878,8477$ \\
\hline Criterion for observed reflections & $I>2 \sigma(I)$ \\
\hline$R_{\text {int }}$ & 0.033 \\
\hline$\theta_{\max }\left({ }^{\circ}\right)$ & 70.2 \\
\hline Range of $h, k, l$ & $-24 \Rightarrow h \Rightarrow 24$ \\
\hline & $-23 \Rightarrow k \Rightarrow 24$ \\
\hline & $-16 \Rightarrow l \Rightarrow 16$ \\
\hline \multicolumn{2}{|l|}{ Refinement } \\
\hline Refinement on & $F^{2}$ \\
\hline$R\left[F^{2}>2 \sigma\left(F^{2}\right)\right], w R\left(F^{2}\right), S$ & $0.058,0.173,1.05$ \\
\hline No. of reflections & 9878 \\
\hline No. of parameters & 737 \\
\hline $\mathrm{H}$-atom treatment & Only coordinates refined \\
\hline Weighting scheme & $\begin{array}{l}w=1 /\left[\sigma^{2}\left(F_{o}^{2}\right)+(0.1099 P)^{2}+\right. \\
\quad 4.6477 P], \text { where } P=\left(F_{o}^{2}+2 F_{c}^{2}\right) / 3\end{array}$ \\
\hline$(\Delta / \sigma)_{\max }$ & 0.041 \\
\hline$\Delta \rho_{\max }, \Delta \rho_{\min }\left(\mathrm{e} \AA^{-3}\right)$ & $0.62,-0.72$ \\
\hline
\end{tabular}

Computer programs: DIP Image plate, Scalepack (HKL), maXus (Mackay et al., 1999), SHELXL97 (Sheldrick, 1997)

zeolite (Chen et al., 1979; Kaeding, 1985; Kaeding et al., 1981; Young et al., 1982; Meshram, 1987). At present, the two widely accepted mechanisms for toluene disproportionation on ZSM5 are:

(i) intermolecular methyl transfer and

(ii) a bimolecular reaction invoking a diphenylmethanetype intermediate.

However, these mechanisms are poorly understood and have been the subject of continuing speculation (Xiong et al., 1995). We have investigated the toluene-ZSM-5 structure by X-ray single-crystal diffraction. In the process we have determined the new high-loaded toluene6.4-ZSM-5 structure and shown three distinct locations of toluene in the crystal with different occupancies and have begun to understand the toluene disproportionation mechanism in the ZSM-5 crystal field. Here we report, for the first time, the new high-loaded toluene6.4-ZSM-5 structure and show the toluene disproportionation reaction in ZSM-5 zeolite.

\section{Experimental}

\subsection{Preparation of ZSM-5}

The ZSM-5 crystals were synthesized by Lermer's method (Lermer et al., 1985). The formal molar composition of the reaction mixture was $\mathrm{SiO}_{2}: \mathrm{NaAlO}_{2}: \mathrm{NaOH}: \mathrm{TPABr}: \mathrm{H}_{2} \mathrm{O}=$ 12:1:40:40:2000. The samples were cooled, washed and dried at $388 \mathrm{~K}$ for $1 \mathrm{~d}$. Cubic crystals were obtained. The Si/Al ratio was found to be over 183 by EDX (Horiba Co. Ltd, EMAX$5770 \mathrm{~W}$ ) and $\mathrm{Na}^{+}$content was not measured. The crystals were treated by $\mathrm{NaClO}_{4}$ and calcined at $823 \mathrm{~K}$ for $12 \mathrm{~h}$. Calcination started at room temperature; the temperature was raised to $823 \mathrm{~K}$ at a rate of $2 \mathrm{~K} \mathrm{~min}^{-1}$ and after a $12 \mathrm{~h}$ hold, lowered down to room temperature at the same rate.

\subsection{Preparation of toluene6.4-ZSM-5}

A freshly prepared ZSM-5 was exposed in a closed vacuum vessel to saturated toluene vapour at room temperature for $2 \mathrm{~d}$. The crystal selected for X-ray analysis measured $0.10 \times 0.07 \times 0.05 \mathrm{~mm}$.

\subsection{Analysis of toluene6.4-ZSM-5}

Cell constants were obtained at $293 \mathrm{~K}$ on a DIP-3200 X-ray diffractometer (Bruker AXS Co. Ltd) with an imaging plate, $\mathrm{Cu} K \alpha$ radiation and an Ni filter. Full experimental details are given in Table 1. ${ }^{1}$ The chemical composition of the toluene 6.4ZSM-5 sample was $\left(\mathrm{CH}_{3} \mathrm{C}_{6} \mathrm{H}_{5}\right)_{6.432}\left[\mathrm{Si}_{96} \mathrm{O}_{192}\right], Z=4$. The 17509 reflections were collected with an imaging plate from the sphere of reflection $(-24 \rightarrow h \rightarrow 24,-23 \rightarrow k \rightarrow 24,-16 \rightarrow l$ $\rightarrow 16$ ), and was corrected for Lorentz polarization and absorption effects but not for the extinction effect. The structure was solved with direct methods (SIR97; Altomare et al., 1999) in the space group $P 2_{1} 2_{1} 2_{1}$ (No. 19) and later refined the structure. It is necessary to shift the origin in the standard $P 2{ }_{1} 2_{1} 2_{1}$ setting to $\left(0,0, \frac{1}{4}\right)^{2}$ for easy comparison with the highloading groups 8PARA (van Koningsveld et al., 1989) and 8PDCB (van Koningsveld, Jansen \& van Bekkum, 1996). The structure was refined by the full-matrix least-squares method (SHELXL97; Sheldrick, 1997) using 8477 observations with $|I|$ $\geq 2 \sigma(I) .\left.\Sigma w|| F_{o}|-| F_{c}\right|^{2}$ was minimized; $w=1 /\left[\sigma^{2}\left(F_{o}^{2}\right)+\right.$ $\left.(0.1099 P)^{2}+4.6477 P\right]$, where $P=\left(F_{o}^{2}+2 F_{c}^{2}\right) / 3$. All $T(T=\mathrm{Si}$, $\mathrm{Al})$ atoms were treated as silicon and $\mathrm{H}$ atoms were included in the calculations. In the final few cycles, three independent toluene molecules were restrained to avoid deformation, i.e. all seven $\mathrm{C}$ atoms of toluene were located in a plane and each methyl carbon of toluene was located the same distance from the attached carbon and the two nearest $\mathrm{C}$ atoms of the benzene ring. The final difference map showed a peak height of $+0.81(3)$ e $\AA^{-3}$. The final $R$ value was 0.058 and the final goodness-of-fit parameter $(S)$ was 1.048 with anisotropic displacement factors. All calculations were performed on the computer system of the National Defense Academy.

\footnotetext{
${ }^{1}$ Supplementary data for this paper are available from the IUCr electronic archives (Reference: BS5009). Services for accessing these data are described at the back of the journal.

${ }^{2}$ The symmetry operations in $P 22_{1} 2_{1} 2_{1}$ become: $x, y, z ; \frac{1}{2}+x, \frac{1}{2}-y, \frac{1}{2}-z$; $-x, \frac{1}{2}+y,-z ; \frac{1}{2}-x,-y, \frac{1}{2}+z$
} 


\section{Results and discussion}

\subsection{Results}

Final positional and equivalent isotropic displacement parameters of high-loaded toluene 6.4-ZSM-5 have been deposited. Figs. 1(a) and $(b)$ show the ZSM-5 zeolite framework and adsorbed toluene molecules at 293 K. Fig. 2 shows an ORTEP3 (Burnett \& Johnson, 1996) drawing in which the three types of toluene molecules in the ZSM-5 framework are highlighted in colour. Two kinds of toluene molecule (TOL1 and TOL2) are located at the intersection of straight and sinusoidal channels, and the other toluene molecule (TOL3) is located in the sinusoidal channel of ZSM-5. In the case of 8PARA or $8 \mathrm{PDCB}$, an additional adsorbed molecule is located at the intersection, while another molecule is located in the sinusoidal channel of ZSM-5. However, the toluene molecule is smaller than the $p$-xylene or $p$-dichlorobenzene molecule, thus two kinds of toluene molecules (TOL1, TOL2) are located in disorder around the intersection. The occupancy factors of TOL1, TOL2 and TOL3 were 0.65 (1), 0.33 (1) and 0.62 (1), respectively, as shown in Fig. 1(a). TOL2 and TOL3

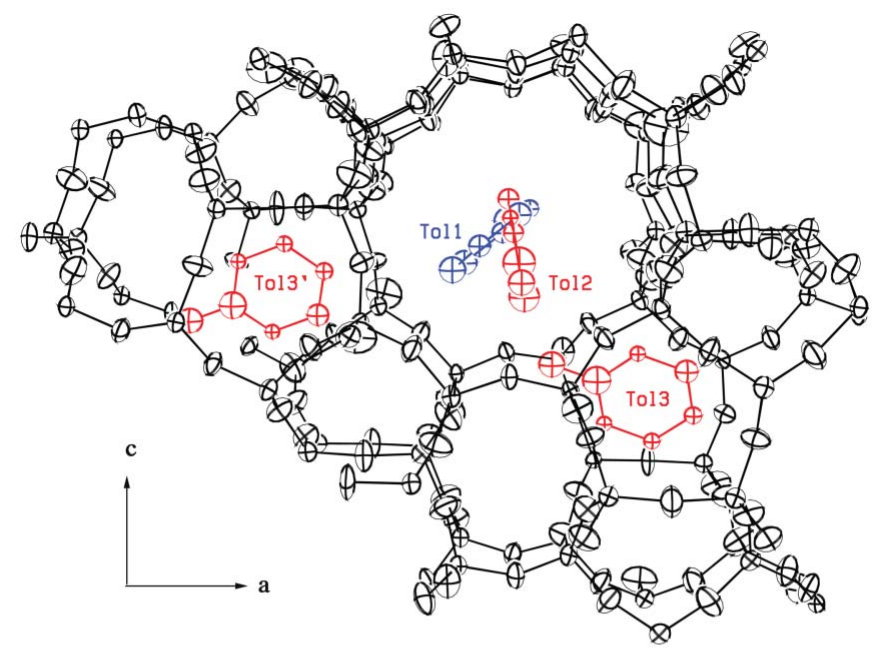

(a)

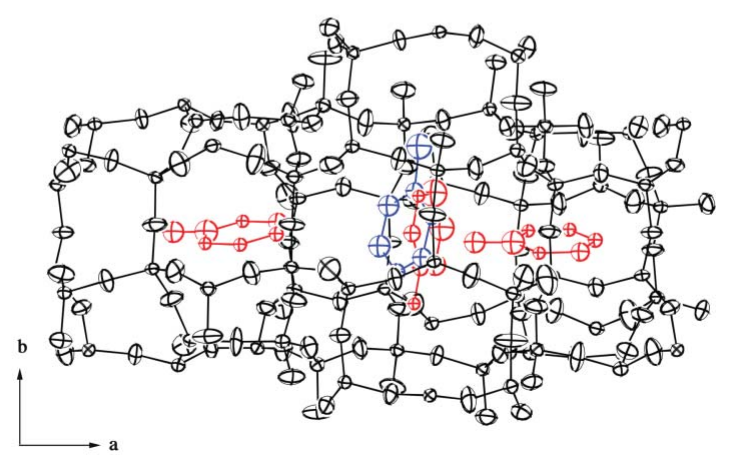

(b)

Figure 1

ORTEP3 drawings (Burnett \& Johnson, 1996) of Tol6.4-ZSM-5. (a) View down the straight channel axis. Tol1 and Tol2 are at the intersection of the channels; Tol3 is in the sinusoidal channel. The occupancy factors are $0.65,0.33$ and 0.62 , respectively. (b) View approximately along [001]. $\mathrm{H}$ atoms are not shown. The ellipsoids are drawn at $50 \%$ probability.
Table 2

Orientation of molecules at the intersection of channels in MFI.

\begin{tabular}{llllll}
\hline & TOL1 & TOL2 & 2.6PDCB & 8PARA & 8PDCB \\
\hline$x$ & 0.4742 & 0.5081 & 0.4860 & 0.5105 & 0.5113 \\
$y$ & 0.2465 & 0.2495 & 0.2400 & 0.2390 & 0.2419 \\
$z$ & -0.0370 & -0.0560 & -0.0188 & -0.0188 & -0.0253 \\
$\alpha 2\left(^{\circ}\right)$ & 52.7 & 171.4 & 47.1 & 149.0 & 153.8 \\
\hline
\end{tabular}

do not form a bond because the shortest distance between the two $\mathrm{C}$ atoms is $2.00 \AA$.

\subsection{Disordering of toluene}

Two kinds of toluene molecules (TOL1 and TOL2) are located in disorder around the intersection. The occupancy factors of TOL1 and TOL2 are 0.65 and 0.33 , respectively, as shown in Fig. 1(a). The TOL1 orientation at the intersection is similar to that of $p$-dichlorobenzene at the intersection in 2.6PDCB. The angle with the positive $a$ axis and the normal on the toluene ring plane $(\alpha 2)$ is $52.7^{\circ}$. The $\alpha 2$ values for 2.6PDCB (van Koningsveld, Jansen \& Man, 1996), $p$-nitroaniline3.7-ZSM-5 (Reck et al., 1996) and naphthalene3.7-ZSM5 (van Koningsveld \& Jansen, 1996) are 47.1, 44.3 and $40.5^{\circ}$, respectively. The TOL1 orientation with a high occupancy factor $(0.65)$ is the first example in the high-loaded group. The TOL2 orientation at the intersection is formally similar to those of $p$-xylene or $p$-dichlorobenzene at the intersection in 8PARA (van Koningsveld et al., 1989) and 8PDCB (van Koningsveld, Jansen 2 angle of TOL2, 8PARA and 8PDCB is $171.4,149.0$ and $153.8^{\circ}$, respectively. However, the occupancy factor of the TOL2 orientation is only 0.33 in the present highloaded toluene/ZSM-5. Table 2 gives the fractional coordinates $(x, y, z)$ and the corresponding $\alpha 2$ of TOL1 and TOL2 at the intersection, together with those of 2.6PDCB, 8PARA and 8PDCB. The TOL2 orientation has a high $\alpha 2$ value (171.4) and a very low $z$ value $(-0.0560)$. This means that TOL2 approaches TOL3 in the sinusoidal channel. However, we question whether or not TOL2 and TOL3 can be occupied simultaneously. The answer is no because the occupancy factor

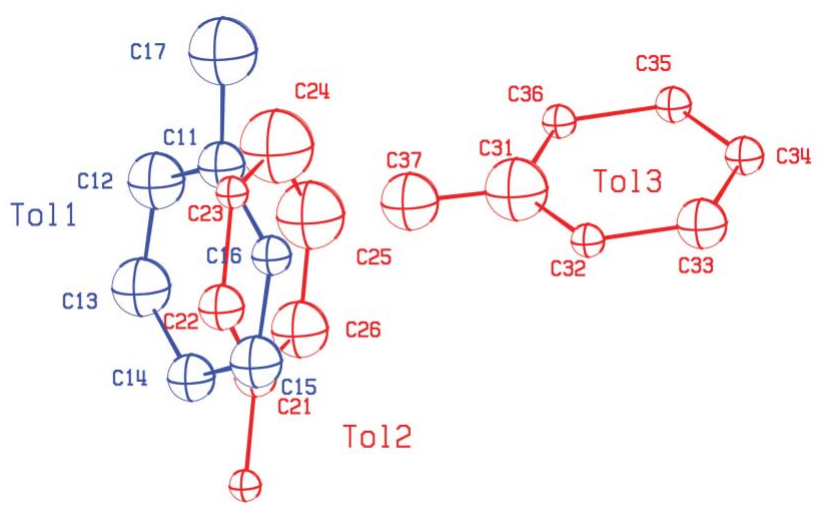

C27

Figure 2

ORTEP (Burnett \& Johnson, 1996) drawing of three kinds of toluene molecule in ZSM-5. 
of TOL3 located in the sinusoidal channel is 0.62 . That is, the contribution of the TOL1 and TOL3 orientations is $c a 65 \%$, while that of TOL 2 and the vacant TOL 3 space is $c a 33 \%$. The shortest bond distance between the two $\mathrm{C}$ atoms of TOL2 and TOL 3 is $2.00 \AA$. This is too long for TOL 2 and TOL 3 to bond with each other.

\subsection{Toluene disproportionation}

It is tempting to speculate on the dynamics of the toluene disproportionation reaction in the ZSM-5 framework. The reaction consists of four steps.

(i) Toluene molecules are adsorbed on ZSM-5, diffuse into the straight channel and are confined at the intersection. This is TOL1 in Figs. 1(a) and (b).

(ii) Toluene molecules diffuse into the sinusoidal channel and are confined there. This is TOL3.

(iii) TOL1 partially transforms into TOL2.

(iv) If the reaction temperature increases, the proportion of TOL2 increases above 33\%. TOL2 and TOL3 become occupied simultaneously and bond with each other.

The combined molecule (TOL2-TOL3) is a diphenylmethaneor diphenylmethane-type cation (Chen et al., 1989). Wu et al. (1998) varied contact time over a wide range to determine which isomer of xylene is the primary product of toluene disproportionation on ZSM-5 and other zeolites. Unfortunately, the results for only ZSM-5 did not reveal which $m$ - or $p$ xylene isomer is preferred. Fig. 2 shows that $m$-xylene is a primary product of toluene disproportionation on ZSM-5.

\section{References}

Altomare, A., Burla, M. C., Camalli, M., Cascarano, G., Giacovazzo, C., Guagliardi, A., Moliterni, A. G., Polidori, G. \& Spagna, R. (1999). J. Appl. Cryst. 32, 115-119.

Burnett, M. N. \& Johnson, C. K. (1996). ORTEP3. Report ORNL6895. Oak Ridge National Laboratory, Tenessee, USA.
Chen, F., Coudurier, G. \& Naccache, C. (1989). Stud. Surf. Sci. Catal. $B, 49,1387-1396$.

Chen, N. Y., Kaeding, W. W. \& Dwyer, F. G. (1979). J. Am. Chem. Soc. 101, 6783-6784.

Eylem, C., Hriljac, J. A., Ramamurthy, V., Corbin, D. R. \& Parise, J. B. (1996). Chem. Mater. 8, 844-849.

Kaeding, W. W. (1985). J. Catal. 95, 512-519.

Kaeding, W. W., Chu, C., Young, L. B. \& Butter, S. A. (1981). J. Catal. 69, 392-398.

Klein, H., Fuess, H., Ernst, S. \& Weitkamps, K. (1994). Micropor. Mater. 3, 291-304.

Koningsveld, H. van (1987). Acta Cryst. B43, 127-132.

Koningsveld, H. van, Jansen, J. C. \& Bekkum, H. van (1996). Acta Cryst. B52, 140-144.

Koningsveld, H. van, Jansen, J. C. \& Man, H. de (1996). Acta Cryst. B52, 131-139.

Koningsveld, H. van \& Jansen, J. C. (1996). Micropor. Mesopor. Mater. 6, 159-167.

Koningsveld, H. van, Tuinstra, F., Bekkum, H. van \& Jansen, J. C. (1989). Acta Cryst. B45, 423-431.

Lermer, H., Draeger, M., Steffen, J. \& Unger, K. K. (1985). Zeolites, 5, 131-134.

Mackay, S., Edwards, C., Henderson, A., Gilmore, C., Stewart, N., Shankland, K. \& Donald, A. (1999). maXus. Chemistry Department, The University of Glasgow, Scotland.

Mentzen, B. F. (1989). J. Appl. Cryst. 22, 100-104.

Meshram, N. R. (1987). J. Chem. Tech. Biotechnol. 37, 111-122.

Olson, D. H., Kokotailo, G. T., Lawton S. L. \& Meier, W. M. (1981). J. Phys. Chem. 85, 2238-2243.

Price, G. D., Pluth, J. J., Smith, J. V., Bennett, J. M. \& Patton, R. L. (1982). J. Am. Chem. Soc. 104, 5971-5977.

Reck, G., Marlow, F., Kornatowski, J., Hill, W. \& Caro, J. (1996). J. Phys. Chem. 100, 1698-1704.

Sheldrick, G. M. (1997). SHELXS97. University of Göttingen, Germany.

Xiong, Y., Rodewald, P. G. \& Chang, C. D. (1995). J. Am. Chem. Soc. 117, 9427-9431.

Yokomori, Y. \& Idaka, S. (1999). Micropor. Mesopor. Mater. 28, 405413.

Young, L. B., Butter, S. A. \& Kaeding, W. W. (1982). J. Catal. 76, 418432.

Wu, P., Komatsu, T. \& Yashima, T. (1998). Micropor. Mesopor. Mater. 22, 343-356. 